\title{
SELF-PRODUCED VIDEOS IN FLIPPED CLASSROOM FOR PRE-COURSE ENGINEERING STUDENTS, ENGINEERING STUDENTS AND NURSING STUDENTS
}

\author{
Joar Sande ${ }^{1}$, Ingvild Leite ${ }^{1}, \&$ Lars Kyte ${ }^{2}$ \\ ${ }^{1}$ Department of Computer Science, Electrical Engineering and Mathematical Sciences, \\ Western Norway University of Applied Sciences (Norway) \\ ${ }^{2}$ Department of Health and Caring Sciences, Western Norway University of Applied Sciences (Norway)
}

\begin{abstract}
Western Norway University of Applied Sciences at Campus Førde offers nursing education, engineering education in electrical engineering and a one-year preparatory course for engineering education. Teachers on the different programs cooperate in the production of video-based resources. The study investigates students' use of videos made by the teacher as part of flipped classroom in three different subjects. These subjects are Control Systems in engineering education, Communication and Norwegian in the preparatory course for engineering education and Anatomy/Physiology in the nursing education. Control Systems, taught in the fourth semester of the engineering education, has traditionally been classroom-based, with a lot of blackboard teaching. Learning sessions have been a combination of problem solving and review on the board. Communication and Norwegian has largely consisted of presentations and related exercises. Anatomy/physiology is part of the course Anatomy, Physiology, Biochemistry and Microbiology, taught in the first semester of the nursing education. Lectures in plenary have traditionally been the most widely used teaching form in this course, but the number of lectures has been reduced in favor of learning sessions in smaller groups. 21 engineering students, 17 nursing students and 17 students in the preparatory engineering course answered a questionnaire about the use of videos. The study shows that the nursing students use videos more before the learning sessions than the other two groups. Videos produced with simple tools are technically satisfactory, and make it easier for the students to understand the material, which contributes to increased learning outcomes. Students express that videos are more motivating, and that they learn more from watching a video than readings. Nursing students expressed a higher degree of agreement to replace the traditional lectures in other topics with videos.
\end{abstract}

Keywords: Inverted classroom, teaching videos, motivation, learning outcomes.

\section{Introduction}

The concept of flipped classroom, also called inverted classroom, is used in different ways with varying content, and it is difficult to point to a common model (Bachnak \& Maldonado, 2014). Flipped classroom means that what has traditionally been done in the classroom is done at home, and what has traditionally been done at home is done in the classroom, but flipped classroom means more than this (Sams \& Bergmann, 2013). Bishop and Verleger, who in a review article have undergone a number of studies on flipped classroom, choose to describe the flipped classroom as a form of teaching that consists of individual computer-based learning outside the classroom and student-active group-based learning in the classroom. Not all concepts referred to as flipped classroom contain these elements (Bishop \& Verleger, 2013). Common to the models referred to as flipped classroom, however, is that the learning that takes place outside the classroom is a preparation for the student-active learning in the classroom. For the model to work, it is a prerequisite that the students have worked with the subject matter beforehand. The guidance in the classroom is based on the knowledge that the students bring with them when they come to the learning sessions, because activating pre-understanding is important for constructing new meaningful knowledge (Pettersen, 2015). It means that the students prepare, preferably by watching one or more videos before the learning session in the classroom. The learning session includes task solving and group work, and the teacher goes from being a lecturer to becoming a supervisor (Sams \& Bergmann, 2013).

Students supplied with videos come better prepared for the learning sessions than those who only get text material in advance (De Grazia, Falconer, Nicodemus, \& Medlin, 2012). In a study among nursing students at Hawaii Pacific University, $85 \%$ of the students thought it was extremely or very useful to watch videos (Critz \& Knight, 2013). Videos can be recordings of whole lectures, or short clips (Kay, 
2012). Previous studies show that short videos are preferred (Guo, Kim, \& Rubin, 2014; Zappe, Leicht, Messner, Litzinger, \& Lee, 2009). Video clips are an important resource for teaching the Internet generation, in order to take advantage of different learning strategies so that each student get better results (Berk, 2009). There are many video lectures on the Internet. However, each lecturer has their own style and it may take a long time to find suitable videos. The time it takes to find a good video online can be as long as the time it takes to make one's own (Raths, 2014). You can start with simple tools, and gradually become more advanced (Sams \& Bergmann, 2013). A large study from the United States shows that what engages most is informal, short video recordings with tablet teaching, as well as videos like those at Khan University. Students like these videos better than even pre-recorded high quality lecture videos (Guo et al., 2014).

A large review of research on flipped classroom concluded that the students are generally positive about this form of learning, but the opinions are somewhat mixed, and some are even negative (Bishop \& Verleger, 2013). Many also prefer a mix of flipped classroom and traditional lectures (Zappe et al., 2009). A survey among engineering students at Texas A \& M International University in a course in electronics, showed that $67 \%$ preferred to continue with the flipped model, while the rest would rather have traditional lectures (Bachnak \& Maldonado, 2014). Another survey among engineering students showed that flipped classrooms meant that lecturer could go through more material, and that the students did just as well as students who had traditional lectures. Initially, the students struggled with the new program, but mastered it quite quickly (Mason, Shuman, \& Cook, 2013).

\section{Objective}

The purpose was to investigate students' use of videos as part of flipped classroom in nursing education, pre-course engineering education and engineering education.

\subsection{Method}

The videos are six to eight minutes long, in central themes. In cases where longer videos have been needed, they have, as far as possible, been divided into shorter clips. The students use the videos as part of their preparation for the learning sessions.

In Control Systems, there are nine major themes, with two or three videos to each main theme, about 20 videos in total. The students were to watch the videos before teaching and learning sessions with a review of theory, followed by a solving of problems in the classroom with access to guidance.

In Communication and Norwegian, students received short videos that they would watch at home or at the start of the class. During class, the students worked on different assignments, oral and written, in both Norwegian and English. There are four main themes in the subject, and each part consisted of between three and five videos.

In Anatomy, Physiology, Biochemistry and Microbiology for the nursing students, "the senses" was selected as the theme, after which 18 short video clips replaced 4 hours of lecture. After watching the videos, the students met in groups for two hours of guidance in the same theme. The subject teacher who met the students for guidance was the same teacher who had recorded the videos.

Some of the videos are made using software that captures the contents of the PC screen while the lecturer talks. The tool used for this is Screencastomatic (Screencastomatic, 2019), which can record both audio and video, used in combination with PowerPoint. Screencastomatic in combination with a web camera was used to record the preparation of notes on paper.

Other videos in the project were recordings, most often of blackboard teaching, made using a rotating camera. Here we used a Swivl robot (Swivl, 2019), which is a tool that, in combination with for example an iPad, records videos. The Swivl robot is rotatable and programmed to follow a marker. The marker can be worn, making the robot follow and record the movements of the lecturer. A built-in microphone records what the lecturer says. The Swivl robot produces mp4 files, a format which most platforms, including smartphones, handle. All videos used in anatomy/physiology were made this way, with the exception of a video made using an animation program. The animation video was made by using a Bamboo drawing board with SmoothDraw, and recorded using a program that captures what is on the screen. This video was saved as a WMV file, and all the charts used were in versions that are available for free on the Internet.

\subsection{Data collection}

In order to evaluate the project, the students answered a questionnaire. The sample consists of 21 engineering students, 17 nursing students and 17 students in the preparatory engineering course. Of these, one engineering student and one student in the preparatory course only answered the first three questions, so that the sample size for these student groups is 20 and 16 students, respectively. Norwegian Center for Research Data (NSD) found that the project was not subject to notification. The students received information in writing and/or oral about the project. They did not provide names on the questionnaires. 


\section{Results}

Table 1 shows the responses of the groups together in the questions where the answers are easy to put together. The "completely agree" and "partially agree" response options are merged to "agree", while the "completely disagree" and "partially disagree" options are merged into "disagree". Students who answered "indifferent" or "don’t know" are not included.

Table 1. Student answers.

\begin{tabular}{|l|l|l|}
\hline Questions. & Agree & Disagree \\
\hline The videos were easy to understand & & \\
\hline The videos worked technically satisfactory & & \\
\hline The videos made it easier to understand the subject matter & & \\
\hline The videos made me well prepared for the learning sessions & & \\
\hline The model with videos and learning sessions is more motivating than lectures & & \\
\hline $\begin{array}{l}\text { The model with videos and learning sessions gave me greater learning outcomes than } \\
\text { lectures }\end{array}$ & ) & \\
\hline I learn more from regular lectures than from the model with videos and learning sessions & & \\
\hline The learning environment during the hours with learning sessions was good & & \\
\hline
\end{tabular}

Table 2 shows the differences between the groups. A Kruskal-Wallis test has been performed by grouping the students' answers, e.g. for the variable "The videos were easy to understand" give "totally agree" the lowest weight and "totally disagree" the highest weight, and then the average weight for the different student groups is shown. Here, too, the students who answered "indifferent" or "don't know" are not included. There are significant differences in how much time students spend on their studies $(\mathrm{p}=0,002)$. A $\mathrm{p}$-value less than 0,05 indicates a significant difference. The nursing students spend the most, the engineering students the least. There is also a significant difference in the use of the videos before learning sessions $(p=0,000)$. Here the nursing students use the videos more than the two other groups. However, after the learning sessions, the engineering students use the videos more than the other groups, but this difference is not significant $(\mathrm{p}=0.069)$. The nursing students are most in agreement with the rest of the questions, with the exception of "I learn more from regular lectures than from the model with videos and guidance/practice". The differences between the student groups are significant $(\mathrm{p}<0.05)$ for all questions, with the exception of "Videos made it easier to understand the subject matter".

Table 2. Comparison of the different student groups' answers to the questions.

\begin{tabular}{|c|c|c|c|c|c|}
\hline \multirow[t]{2}{*}{ Questions. } & \multicolumn{3}{|c|}{$\begin{array}{l}\text { Group, mean rank. } \\
\text { Lower number values indicate a higher } \\
\text { degree of agreement. }\end{array}$} & \multicolumn{2}{|c|}{$\begin{array}{c}\text { Kruskal-Wallis test. } \\
\text { A p-value less than } 0,05 \text { is a } \\
\text { significant difference. }\end{array}$} \\
\hline & Nursing & Engineer & Preparatory course & Chi-squared & p-value \\
\hline Time spent & & & 33,8 & 12,47 & 0,002 \\
\hline Use of video before learning sessions & & & 32,3 & 23,69 & 0,000 \\
\hline Use of video after learning sessions & & & 30,5 & 5,35 & 0,0069 \\
\hline The videos were easy to understand $*$ & & & 33.4 & 10,79 & 0,005 \\
\hline \multicolumn{6}{|l|}{$\begin{array}{l}\text { The videos worked technically } \\
\text { satisfactory * }\end{array}$} \\
\hline \multicolumn{6}{|l|}{$\begin{array}{l}\text { The videos made it easier to understand } \\
\text { the subject matter * }\end{array}$} \\
\hline $\begin{array}{l}\text { The videos made me well prepared for } \\
\text { the learning sessions* }\end{array}$ & & & 30.6 & 14,53 & 0,001 \\
\hline $\begin{array}{l}\text { The model with videos and learning } \\
\text { sessions is more motivating than } \\
\text { lectures * }\end{array}$ & & & 26.7 & 7,92 & 0,019 \\
\hline $\begin{array}{l}\text { The model with videos and learning } \\
\text { sessions gave me greater learning } \\
\text { outcomes than lectures * }\end{array}$ & & & 25.7 & 7,11 & 0,029 \\
\hline \multicolumn{6}{|l|}{$\begin{array}{l}\text { I learn more from regular lectures than } \\
\text { the model with videos and learning } \\
\text { sessions** }\end{array}$} \\
\hline $\begin{array}{l}\text { The learning environment during the } \\
\text { hours with learning sessions was good } \\
* *\end{array}$ & & & 33.2 & 6,69 & 0,035 \\
\hline
\end{tabular}


$26,7 \%$ of the engineering students, $94,9 \%$ of the nursing students and $71,4 \%$ of the pre-course students want to replace lectures with videos and learning sessions in other topics. Fisher's exact test shows that there is a significant difference between the groups in this question $(\mathrm{p}=0.001)$. In this test, "do not know" answers are ignored.

\section{Discussion}

The students clearly stated that videos made with easily accessible tools that the individual teacher can produce without assistance from others, were technically satisfactory. This is in line with what previous experience has shown. You do not need expensive and advanced equipment to make videos that work well technically (Sams \& Bergmann, 2013). Videos recorded with simple and inexpensive equipment, and where the teacher has good eye contact with the viewer, can be more engaging for the students than videos produced in a professional studio (Guo et al., 2014). Our opinion is that the videos must be of sufficient quality, but do not need to be perfect. A common teaching situation is not perfect either.

Although all student groups were generally positive to flipped classroom, there are significant differences. The nursing students used videos more than pre-course and engineering students did before the learning sessions. Compared to the other groups, more nursing students also expressed that they felt this was a good way to prepare for the upcoming sessions, which would explain why they spent more time watching videos. This is consistent with the Hawaii Pacific University survey, where $85 \%$ of nursing students thought it was extremely or very useful to watch videos (Critz \& Knight, 2013). Video clips can make a difference when it comes to students' motivation and attitude to the subject (Berk, 2009), and a clear majority of nursing students in our study think videos are more motivating than lectures.

The nursing students are also generally the most satisfied with the videos, they agree more that the videos are easy to understand and that they were technically satisfactory, than the other two student groups. The nursing students also have higher degree of agreement that the video and learning session model provides greater learning outcomes than lectures, while only a minority of pre-course and engineering students agree. Unlike nursing students, only a minority of engineering students believe that the teaching model in our study is more motivating than lectures.

These differences between the student groups may have several possible explanations. An explanation can be the way they use the videos, where the nursing students have used the videos more to prepare for the learning sessions. Another explanation may be the content of the videos, which in turn has a certain connection with the specificities of the subjects (Kay, 2012). Anatomy is a visual subject with many illustrations that can be good on video. The videos used in anatomy and physiology for nursing students were short, and made using a camera to record tablet teaching. When the students in our study were satisfied with this video format, it corresponds to the major review of flipped teaching in the United States that shows that short, informal tablet recording videos are most engaging (Guo et al., 2014).

The engineering students are generally more inclined to have lectures than the other student groups, and there are different reasons why students prefer lectures rather than videos (Kay, 2012). One reason why many of the engineering students in our study prefer lectures may be that they are most accustomed to blackboard teaching, and that the videos do not reflect the usual teaching situation. Working with control systems includes many mathematical calculations, and most videos are recordings of calculations on paper without the video showing a picture of the lecturer. The students want to both see and hear lecturers, so that the videos become more similar to other teaching situations (Guo et al., 2014; Sams \& Bergmann, 2013).

The most surprising finding is that the nursing students, more than the engineering students, want to replace more of the teaching with videos and learning sessions. The difference between the student groups is significant. We thought the engineering students, who are more technically oriented, were more accustomed to finding and using videos in their learning. There are plenty of videos on YouTube on most technical topics, and videos support multiple learning strategies (Berk, 2009). Based on this, we assumed that the engineering students would prefer their study material presented in videos. The result of our study, however, was different. If we see the students' answers to this question in connection with what they answered to other questions, it is not as surprising as it might be at first glance. Although all the student groups are satisfied with the technical level of the videos, the nursing students are significantly more satisfied than the engineering students are. An explanation can be the technical differences between the videos, but may also indicate that the engineering students, because of their technical competence, have higher technical demands than the nursing students do. Another possible explanation for the engineering students being less enthusiastic, is the format of the videos. As mentioned earlier, the students in engineering education are mostly accustomed to blackboard teaching, while most of the videos are recording of computer screens or notes. Videos should therefore look more like the usual teaching situation, and visualize the material in a good way. The previously mentioned study from the United States (Guo et al., 2014) shows that short videos with the recording of tablet teaching are the best. 


\section{Conclusion}

In this study, we have tested out self-produced videos as part of flipped classroom for nursing students, engineering students and students on a preparatory engineering course. Overall, the students expressed that the videos were both easy to understand and helped them to understand the subject matter more easily. One factor that may have contributed to how well they were received, was that the videos were short and often dealt with one single theme. The students found the videos technically satisfactory, which is important for how they would be used. The study supports the fact that videos made with simple tools work well both technically and academically. However, there were some clear differences between the student groups. The nursing students were even more satisfied with the learning model than the engineering students and pre-course students. Compared to the other student groups, the nursing students expressed that this model provided greater learning outcomes and was more motivating.

\section{References}

Bachnak, R., \& Maldonado, S. C. (2014). A flipped classroom experience: Approach and lessons learned. In ASEE national conference proceedings (Vol. 2014).

Berk, R. A. (2009). Multimedia teaching with video clips: TV, movies, YouTube, and mtvU in the college classroom. International Journal of Technology in Teaching \& Learning, 5(1).

Bishop, J. L., \& Verleger, M. A. (2013). The flipped classroom: A survey of the research. In ASEE national conference proceedings, Atlanta, GA (Vol. 30, No. 9, pp. 1-18).

Critz, C. M., \& Knight, D. (2013). Using the flipped classroom in graduate nursing education. Nurse educator, 38(5), 210-213.

De Grazia, J. L., Falconer, J. L., Nicodemus, G., \& Medlin, W. (2012). Incorporating screencasts into chemical engineering courses. Paper presented at the 2012 ASEE Annual Conference \& Exposition.

Guo, P. J., Kim, J., \& Rubin, R. (2014). How video production affects student engagement: an empirical study of MOOC videos. In Proceedings of the first ACM conference on Learning@ scale conference (pp. 41-50). ACM.

Kay, R. H. (2012). Exploring the use of video podcasts in education: A comprehensive review of the literature. Computers in Human Behavior, 28(3), 820-831.

Mason, G. S., Shuman, T. R., \& Cook, K. E. (2013). Comparing the effectiveness of an inverted classroom to a traditional classroom in an upper-division engineering course. IEEE Transactions on Education, 56(4), 430-435.

Pettersen, R. C. (2005). Kvalitetslaering $i$ høgere utdanning: innføring $i$ problem-og praksisbasert didaktikk: Universitetsforlaget.

Raths, D. (2014). Nine video tips for a better flipped classroom. The Education Digest, 79(6), 15.

Sams, A., \& Bergmann, J. (2013). Flip your students' learning. Educational leadership, 70(6), 16-20.

Screencastomatic. Video creation for everyone. Retrieved 06.18.2019 from https://screencast-omatic.com/

Swivl. Video observations that strengthen and inform teachers. Retrieved 06.18.2019 from https://www.swivl.com/

Zappe, S., Leicht, R., Messner, J., Litzinger, T., \& Lee, H. W. (2009). " Flipping" the classroom to explore active learning in a large undergraduate course. In ASEE Annual Conference and Exposition, Conference Proceedings. 